\title{
Safety Motivation and Work Pressure as Predictors of Occupational Accidents in the Petrochemical Industry
}

\author{
Tayebe Rahimi Pordanjani $^{1, *}$ and Ali Mohamadzade Ebrahimi ${ }^{1}$ \\ ${ }^{1}$ Department of Psychology, Faculty of Humanities, University of Bojnord, Bojnord, IR Iran \\ *Corresponding author: Tayebe Rahimi Pordanjani, Department of Psychology, Faculty of Humanities, University of Bojnord, Bojnord, IR Iran. Tel: +98-5832284611, Fax: +98-5832284634 \\ E-mail: tayebe.rahimi@yahoo.com
}

Received: January 13, 2015; Revised: July 2, 2015; Accepted: July 9, 2015

\begin{abstract}
Background: The best way to reduce occupational injury and accident rates seems to be to investigate the social and organizational factors influencing workplace safety.

Objectives: The present study examines relationships of safety motivation and work pressure with occupational accident rate among workers of Khorasan petrochemical company.

Patients and Methods: In this cross-sectional study, the population consisted of all line employees working in Khorasan petrochemical company $(\mathrm{n}=1160)$. Stratified sampling was used to select 300 employees. They completed measures of safety motivation, perceived work pressure, and incident reporting rate. Regression analysis was performed by SPSS software in main stage and confirmatory factor analysis was performed by AMOS software in validation stage.

Results: Both safety motivation and work pressure were significantly correlated with occupational accident rate $(\mathrm{P}<0.0001)$. Stepwise multiple regression analyses showed that both safety motivation and work pressure were significant predictors $\left(\mathrm{R}^{2}=0.302, \mathrm{P}<0.0001\right)$. Conclusions: Safety motivation and work pressure are important predictors of occupational accident rate. Therefore, increasing safety motivation and reducing work pressure in high-risk jobs are effective ways in which organizations can decrease occupational accident rates.
\end{abstract}

Keywords: Accidents, Occupational; Motivation; Pressure; Safety; Work

\section{Background}

According to recent accident statistics, 4900 deaths and 3.7 million disabling injuries occurred in American workplaces. However, data from the National Safety Council (NSC) on occupational injuries and deaths rates are likely to be underestimated $(1,2)$, because the cost of work injuries and deaths will be much higher than the NSC estimate (3) if the following are accounted for: noneconomic consequences of injury and accidents, such as pain and suffering experienced by workers and their families, decreased social functioning, and negative impact on family and workplace relationships (3). According to the Iranian Legal Medicine Organization, in the first seven months of 2012, 1,101 people were killed in workrelated accidents, a $24 \%$ increase over the same period in 2011 (4). Therefore, the best way to reduce occupational injury and accident rates seems to be to investigate the social and organizational factors influencing workplace safety (5). One such factor is employees' motivation to work safely (6).

Safety motivation refers to an individual's willingness to engage in safety behaviors and the value attached to those behaviors (7). The purpose of safety motivation is preventing accidents and injury at the desirable safety level by using scientific principles and procedures. Safety motivation influences adherence to safety procedures, and has been found to ensure safety of not only individuals but also organizations and even society (8).

Although employee safety motivation has been considered important since the beginning of the twentieth century, researchers have only lately begun systematic research on this construct. Most research has emphasized the effect of worker safety motivation on injury and accident rates, and indicates that organizations can influence workers unsafe behaviors both directly and indirectly by influencing workers safety motivation (7, 9-11). Zohar (12) indicated that employee safety motivation can influence unsafe work behavior and consequent occupational accidents. People can be motivated to improve their behavior according to cultural norms if they perceive that compliance will lead to a desirable outcome (13).

Moreover, a number of safety researchers have examined how performance pressure can influence safety

Copyright (C) 2015, Health Promotion Research Center. This is an open-access article distributed under the terms of the Creative Commons Attribution-NonCommercial 4.0 International License (http://creativecommons.org/licenses/by-nc/4.0/) which permits copy and redistribute the material just in noncommercial usages, provided the original work is properly cited. 
within organizations. Work pressure, which is composed of excessive workload, excessive work pace, and time constraints, has been revealed to be a causal factor of both occupational accidents and unsafe work behavior (3). Work pressure increases the likelihood that an individual will engage in accidents by adopting "short cut" work methods (14). Furthermore, in the face of time constraints, individuals can begin to perceive that risk taking is part of their work. In other words, individuals realize that there is not enough time to follow safe practices (14). Work pressure is likely to lead to increased psychological stress among workers, which in turn increases the probability of occupational accidents (3). Thus, workers will ignore safe procedures when they feel the need to act quickly. These short cuts or unsafe behaviors often become the norm since they allow employees to perform tasks much more quickly and effectively (15).

Lusa et al.(16) reported that working overtime increased the risk of accidents among firefighters in 71 fire brigades in Finland. They indicated that working more than 70 hours per week compared with working no more than 50 hours per week increases the risk of job-related accidents (16). Flin et al. (17) showed that work pressure influences safety and performance in the workplace because of inadequate resources and time constraints.

\section{Objectives}

Against this background, the aim of the present study is to examine how safety motivation and work pressure are related to occupational accident rate. Most previous studies have focused on special industries, and none has targeted petrochemical industry employees, especially in Iran.

\section{Patients and Methods}

In this cross-sectional study, the population consisted of all line employees of Khorasan petrochemical company in Bojnord, Iran $(\mathrm{n}=1160)$. Stratified random sampling was used to select 300 employees. This method of sampling involves the division of a population into smaller groups known as strata. The strata are formed based on members' shared attributes or characteristics (business unit as well as employment status in present study). Then, each employee received the questionnaire in person at the workplace, completed it, and returned it to the researcher. Participants gave written informed consent. The measures used were score on a safety motivation scale, perceived work pressure scale, and incident reporting rate.

\subsection{Safety Motivation Scale}

Salleh (18) developed a 4-item measure of safety motivation in petrochemical industries. Three items were derived from Neal and Griffin (7) and one item was derived from Zacharatos (2001). A sample item is "I believe that it is important to reduce the risk of occupation accidents and incidents." Responses were measured on a 5-point Likert type scale (strongly disagree 1 - strongly agree 5). Higher scores reflect higher employee motivation. Salleh (18) confirmed that this scale had validity through principle component analysis (PCA). It also has high internal consistency reliability (Cronbach's $\alpha=0.99-0.72)(7,11)$. In the current study, Cronbach's $\alpha$ and Spearman-Brown coefficients were 0.90 and 0.89 , respectively.

\subsection{Perceived Work Pressure}

A 7-item scale based on a set of 25 items was used to measure perceived work pressure such as excessive workload, excessive work pace, and time constraints (3). A sample item is "We are often in such a hurry that safety is temporarily overlooked." Responses were measured on a 5-point Likert type scale and ranged from "strongly disagree" (1) to "strongly agree" (5). Higher scores reflect higher employee motivation. Seo reported that Cronbach's $\alpha$ is 0.88 and that this questionnaire has good validity $(3,19)$. In the current study, Cronbach's $\alpha$ and Spearman-Brown coefficients were 0.79 and 0.77 , respectively.

\subsection{Incident Reporting Rate Scale}

This tool was developed by Barling, Loughlin and Kelloway (20). It consists of three subscales: physical symptoms (11 items), psychological symptoms (6 items), and accidents (10 items) (20). It has high internal reliability (Cronbach's $=0.70-0.80$ ) and also good validity (21). Kiani et al. administered this scale to an Iranian sample in Isfahan Steel Company and found Cronbach's $\alpha$ to be 0.83 (22). In the current study, Cronbach's $\alpha$ for the full scale and its components were 0.93, 0.86, 0.87, and 0.85, respectively.

Confirmatory factor analysis was performed by AMOS software toto assess the construct validity of the measures used in this study. Fit indices are shown in Table 1.

\section{Results}

\subsection{Demographic Characteristics}

Findings are presented in three sections: demographic data, descriptive statistics, and regression results. Demographic characteristics of participants are shown in Table 2.

\subsection{Descriptive Statistics}

Descriptive statistics, consisting of the number of items, range, means, standard deviations, and internal correlation coefficients, of safety motivation, work pressure, and occupational accident rate are presented in Table 3.

Table 3 indicates that correlation coefficient between occupational accident rate and safety motivation is - 0.468 and the coefficient between occupational accident rate and work pressure is 0.430 (Ps $<0.0001$ ). These results confirm all hypotheses. The results pertaining to the 
third hypothesis, that is, there is a multiple correlation between safety motivation and work pressure with occupational accident rate, are shown in Table 4. Regression analysis indicates that safety motivation and work pressure have a significant multiple correlation (0.550) with occupational accident rate, and explain $30.2 \%$ of variance in it (Table 4). One of the main assumptions of the regression analysis is normal distribution of variables. In the present study, normality was assessed by calculating kurtosis and skewness. In general, if kurtosis and skew- ness statistics are outside the range of -3 to 3 , the data are not normally distributed (18). Normality test results are shown in Table 3.

\subsection{Regression Analysis}

Stepwise regression analysis was used to assess the predictive power of safety motivation and work pressure for occupational accident rate. The results are presented in Table 4.

Table 1. Model Fit Indices for Questionnaires in the Current Study, Obtained From Confirmatory Factor Analysis

\begin{tabular}{lccccccccc}
\hline Variables & RMSEA & NFI & CFI & TLI & IFI & AGFI & GFI & $\chi^{2} /$ df & \\
\hline Safety motivation scale & 0.09 & 0.99 & 0.99 & 00.98 & 0.95 & 0.94 & 0.98 & 3.77 \\
Perceived work pressure & 0.07 & 0.95 & 0.97 & 00.94 & 0.97 & 0.93 & 0.97 & 2.59 & 31.17 \\
Incident reporting rate & 0.09 & 0.83 & 0.87 & 0.84 & 0.87 & 0.71 & 0.77 & 3.65 & 1068.04 \\
\hline
\end{tabular}

Table 2. Demographic Characteristics of the Sample $(n=300)^{a}$

\begin{tabular}{|c|c|}
\hline Demographic Variables & Values \\
\hline \multicolumn{2}{|l|}{ Age, y } \\
\hline $18-25$ & 2 \\
\hline $26-33$ & 23 \\
\hline $34-42$ & 38 \\
\hline $43-49$ & 32 \\
\hline$\geq 50$ & 5 \\
\hline \multicolumn{2}{|l|}{ Gender } \\
\hline Male & 98 \\
\hline Female & 2 \\
\hline \multicolumn{2}{|l|}{ Marital status } \\
\hline Married & 93 \\
\hline Single & 7 \\
\hline \multicolumn{2}{|l|}{ Education } \\
\hline Master's degree & 2 \\
\hline Bachelor's degree & 32 \\
\hline High school graduates & 17 \\
\hline Primary school and lower & 49 \\
\hline \multicolumn{2}{|l|}{ Work experience, y } \\
\hline$\leq 5$ & 14 \\
\hline $6-10$ & 15 \\
\hline $11-15$ & 17 \\
\hline $16-20$ & 41 \\
\hline$\geq 21$ & 13 \\
\hline \multicolumn{2}{|l|}{ Shift status } \\
\hline Shift & 44 \\
\hline Not shift & 56 \\
\hline
\end{tabular}


Rahimi Pordanjani Tet al.

\begin{tabular}{|c|c|c|c|c|c|c|c|c|}
\hline \multirow{2}{*}{ Variables } & \multicolumn{8}{|c|}{ Correlations } \\
\hline & Number of Items & Range & Skewness & Kurtosis & Mean \pm SD & $\mathbf{1}$ & 2 & 3 \\
\hline Safety motivation & 4 & $4-20$ & -1.794 & 1.430 & $18.28 \pm 2.45$ & 1 & & \\
\hline Work pressure & 7 & $7-32$ & 0.178 & -0.278 & $17.29 \pm 5.10$ & -0.338 & 1 & \\
\hline Occupational accident rate & 10 & $10-42$ & 1.410 & 1.568 & $17.12 \pm 7.21$ & -0.468 & 0.430 & 1 \\
\hline
\end{tabular}

\begin{tabular}{|c|c|c|c|c|c|}
\hline \multirow{2}{*}{ Variable } & \multirow{2}{*}{ MR } & \multirow{2}{*}{ RS } & \multirow{2}{*}{$\mathbf{F}, \mathbf{P}$} & \multicolumn{2}{|c|}{ Beta } \\
\hline & & & & Step 1 & Step 2 \\
\hline \multicolumn{6}{|c|}{ Occupational accident rate } \\
\hline Safety motivation & 0.468 & 0.219 & $73.631, \mathrm{P} \leq 0.0001$ & $\begin{array}{c}\beta=-0.468, t=-8.581 \\
P \leq 0.0001\end{array}$ & - \\
\hline Work pressure & 0.550 & 0.302 & $56.692, \mathrm{P} \leq 0.0001$ & $\begin{array}{c}\beta=-0.364, t=-6.642, \\
P \leq 0.0001\end{array}$ & $\begin{array}{c}\beta=0.307, t=5.593, \\
P \leq 0.0001\end{array}$ \\
\hline
\end{tabular}

\section{Discussion}

The purpose of this study was to investigate the relationship of safety motivation and work pressure with occupational accident rate. Safety motivation was found to have a significant negative correlation with occupational accident rate (-0.468). These results are consistent with previous findings (Neal and Griffin (7), Ying et al. (8) Griffin and Neal (9), Christian et al. (10) Vinodkumar and Bhasi (11), and Zohar (12)). Safety motivation reinforces employees' safety behaviors, increases employees' participation in safety meetings and setting safety goals, and encourages employees to present safety suggestions that improve safety performance (9). Safety motivation promotes adherence to safety procedures, and has been found to ensure safety of not only individuals but also organizations or even society (8). Expectancy-valence theory predicts that workers will be motivated to engage fully in safety practices and participate in safety meetings if they believe that these behaviors will lead to desirable outcomes $(7,13)$.

Work pressure was also found to have a significant positive correlation with occupational accident rate (0.430). These results are consistent with other findings (e.g. Seo (3), Hofmann and Stetzer (14) and Mullen (15)). An explanation of these findings could be that work pressure appears to be a causal factor of both accident rates and unsafe work behavior (3). Work pressure increases the likelihood that an individual will engage in unsafe behaviors by adopting short-cut work methods (14). Further, work pressure would likely lead to increased psychological stress among workers, which in turn increases the probability of involvement in occupational accidents (3). Thus, workers will ignore safe procedures when they feel the need to act quickly. These short cuts or unsafe behaviors often become the norm since they allow employee to perform tasks much more quickly and effectively (15). The present results emphasize the role of safety motivation and work pressure in the prediction of occupational accident rate. Therefore, organizations can effectively lower occupational accident rates by identifying critical antecedents of occupational accidents and investigating why people are motivated to work safely. Managers should attempt to enhance safety by focusing on changing the organization environment to motivate people to effectively participate in safety activities, rather than simply reproaching and penalizing individuals who have been injured. Another effective measure could be rewarding employees who have adhered to all safety guidelines and not been involved in any incident during a specific period; this could include informational (feedback or self-recording), social (praise or recognition), or tangible reinforcements (trading stamps or cash bonuses) as well as nonmonetary privileges (13). Further, to increase safety motivation, workers must be able to understand what the motivation program is designed to accomplish and how their performance will be evaluated. Another recommendation is that employers reduce work pressure in the high-risk jobs. These findings provide valuable guidance for researchers and management for identifying measures by which they can reduce workplace injury and accident rates.

It is important to highlight some limitations of the present study, which can guide future studies. First, the use of self-report questionnaires may have limitations. Answers may be affected by deliberate distortions and inaccuracies. A combination of self-report measures and objective assessments (e.g., interviews) would be suitable. Second, the results are neither limited to the studied organization nor necessarily applicable to all types 
of organizations. Finally, the current results should be carefully interpreted. Longitudinal research is needed to clarify the causal relations of safety motivation and work pressure with occupational accident rate.

\section{Acknowledgements}

This study was supported by Khorasan petrochemical company. The authors thank all workers who participated in this survey as well as the HSE department of the company.

\section{Authors' Contributions}

Tayebe Rahimi Pordanjani and Ali Mohamadzade Ebrahimi equally participated in all stages of this study (design, data management, data analysis, and writing of the manuscript).

\section{References}

1. National Safety Council. Injury facts 2005-2006. Itasca, IL; NSC. 2006.

2. Leigh JP, Waehrer G, Miller TR, Keenan C. Costs of occupational injury and illness across industries. Scandinavi J Work Environ Health. 2004:199-205.

3. Seo DC. An explicative model of unsafe work behavior. Saf Sci. 2005;43(3):187-211.

4. Legal Medicine Organization. Work-related deaths in the first seven months of 2012. Available from: http://www.jamejamoline.ir.

5. Lee TR, editor. The role of attitudes in the safety culture and how to change them.; a conference on Understanding Risk Perception, Offshore Management Centre, Aberdeen.; 1995; p. 147.

6. Fleming M. Assessing employee safety motivation. Richmond: The Workers' Compensation Board of BC. 2012.

7. Neal A, Griffin MA. A study of the lagged relationships among safety climate, safety motivation, safety behavior, and accidents at the individual and group levels. J Appl Psychol. 2006;91(4):946-53.

8. Ying L, Zhijia H, Lianbao L. Motivation Mechanism of Accident Prevention in Coal Mine. Procedia Eng. 2012;43:174-9.

9. Griffin MA, Neal A. Perceptions of safety at work: a framework for linking safety climate to safety performance, knowledge, and motivation.J Occup Health Psychol. 2000;5(3):347-58.

10. Christian MS, Bradley JC, Wallace JC, Burke MJ. Workplace safety: a meta-analysis of the roles of person and situation factors.J App Psychol. 2009;94(5):1103-27.

11. Vinodkumar MN, Bhasi M. Safety management practices and safety behaviour: assessing the mediating role of safety knowledge and motivation. Accid Anal Prev. 2010;42(6):2082-93.

12. Zohar D. Safety climate in industrial organizations: theoretical and applied implications. J Appl Psychol.1980;65(1):96-102.

13. Lu CS, Yang CS. Safety climate and safety behavior in the passenger ferry context. Accid Anal Prev. 2011;43(1):329-41.

14. Hofmann DA, Stetzer A. A Cross-Level Investigation of Factors Influencing Unsafe Behaviors and Accidents. Pers Psychol. 1996;49(2):307-39.

15. Mullen J. Investigating factors that influence individual safety behavior at work. J Safety Res. 2004;35(3):275-85.

16. Lusa S, Hakkanen M, Luukkonen R, Viikari-Juntura E. Perceived physical work capacity, stress, sleep disturbance and occupational accidents among firefighters working during a strike. Work Stress. 2002;16(3):264-74.

17. Flin R, Mearns K, O'Connor P, Bryden R. Measuring safety climate: identifying the common features. Saf Sci. 2000;34((1-3)):177-92.

18. Salleh A. Safety behavior in the Malaysian petrochemical industry. [PhD thesis.]. Malaysia: University of Utara Malaysia; 2010.

19. Brown KA, Willis PG, Prussia GE. Predicting safe employee behavior in the steel industry: Development and test of a sociotechnical model.J Oper Manag. 2000;18(4):445-65.

20. Barling J, Loughlin C, Kelloway EK. Development and test of a model linking safety-specific transformational leadership and occupational safety. JAppl Psychol. 2002;87(3):488-96.

21. Munteanu MR. Safety attitudes in the Ontario construction. [MS thesis.]. Toronto: University Toronto; 2005.

22. Kiani F, Samavatyan H, Pourabdian S, Jafari E. Predictive Power of Incidents Reporting Rate and Its Dimensions by Job Stress among Workers' Isfahan Steel Company. Iran J Public Health. 2011;40(3):105-12. 